\title{
Circular Motion, the Same and the Other, logos, and Cognition
}

\author{
(Tim. 37a5-c3)
}

Josef Moural

I. Arguably, one main point in Plato's philosophy is the challenge that each of us should care for one's soul rather than for anything else, and the cognitive capacity of the soul is supposed to play a major role in that undertaking. Hence the importance of studying Plato's descriptions of various types of cognition and their relation to the soul. Specifically, given that the soul's basic feature is to be in motion, it seems natural to look for the description of cognition in terms of soul's motion.

In fact, Plato provides such descriptions in various passages, mainly in the so-called middle and late dialogues. These descriptions are sometimes neglected by the students of Plato's theory of knowledge, presumably because they are too brief and not quite intelligible. Still, they recur often enough in Plato to be worth of, at least, questioning seriously what we understand in them, and what we do not.

Although my primary interest is in the cognitive capacities of the human soul, in this paper I shall deal with the passage 37a5-c3 which concerns cognitive capacities of the World-Soul. My questions will focus on the role of the circular motion, of the opposition the Same/the Other, and 
of logos in various types of cognition. Unfortunately, my discussion of possible answers will remain inconclusive on several points.

II. The passage Tim. 37a5-c3 (hotan...) is known as difficult and open to various ways of reading. Given both the limited space and the limits of my erudition let me refer on that to the admirable commentary by Mr. Luc Brisson. ${ }^{\mathrm{i}}$ Although I am going to propose tentatively an alternative reading of 37b1-3, let me start with a summary of the passage's contents as it is usually read (watering down or leaving out some possible discrepancies):

[1] ...whenever the World-Soul touches (efaptétai) a substance, be it a dispersed (skedastén) or an undivided (ameriston) one, it moves thoroughly and using logos determines what the substance in question is the Same with and what it is Other than, in what respect, where, how, and when, both in the sphere of things becoming and with regard to things that are always changeless. [37a5-b3]

\footnotetext{
i Brisson, L., Le même et l'autre dans la structure ontologique du Timée de Platon: Un commentaire systématique du Timée de Platon, Éditions Klincksieck, Paris 1974. He discusses the relative plausibility of the three traditional ways of global grammatical construction of the key part of the first sentence (37a5-b3), distinguished by Proclus (In Tim. II, 302.16-303.13), as dependent on one's choice in three other local ambiguities [pp. 342347], as well as some difficulties of the second sentence [pp. 347-351]. See also commentaries by; A. E. Taylor, Commentary on Plato's Timaeus, (1928), pp. 177-178, and Cornford, Plato's Cosmology: The Timaeus of Plato, (1937), pp. 94-95.
} 


\section{AIOHP}

[2] Logos true both concerning the Other and the Same is born without speech and sound, [37b3-6]

[3] and when concerned with the sensible (aisthéton) and the circle of the Other moves correctly and proclaims (diangeilé) throughout the Soul, beliefs and opinions true and firm are born, [37b6-8]

[4] and when concerned with the rational (logistikon) and the circle of the Same moves correctly and announces (ménusé), the result is nous and knowledge. [37c1-3]

Let me point out immediately at the tension between (i) the specialization of the circles suggested in [3] and [4], where the soul seems to be said to cognize the sensibles by means of the circle of the Other, and the intelligibles by means of the circle of the Same, and (ii) the cooperation of the circles suggested in [1] where, regardless what kind of object is cognized, it is the whole soul that moves, and sameness as well as otherness are predicated. The recognition of that tension gave direction to my inquiry. Given the limited space, however, I shall do only little more besides analyzing the passage in question regarding four aspects, namely (a) what is cognized by the World-Soul (the objects of cognition), (b) what the cognition consists of, i.e. what is predicated about the objects, (c) the epistemological status of various types of cognition, and (d) the involvement of logos and of some kind of internal communication in the cognition. 
III. (a) When asking 'what is cognized' by the World-Soul we have to bear in mind that there is nothing outside it that could enter it (33c), and that it does not have certain sense organs, namely those of sight and hearing (33c). Given that, how are we supposed to understand the word efaptétai in [1]? I see two possible ways to answer, and I propose to see them as complementary rather than mutually exclusive.

One answer is that the tactile sense was not explicitly ruled out by Plato (unlike the visual and auditive), and that the world animal clearly could have some sensations about what goes on in its body. The second answer takes the word efaptétai in a less narrow sense, i.e. as meaning just some kind of intentional directedness towards the object. ${ }^{i}$ While considering the former answer I am rather indifferent (I guess that to accept it would probably not do much harm - and anyway, in the case of the human soul there will be plenty of sensations to deal with). I suggest that we have to embrace the latter answer, since among the objects 'touched' there are also the intelligible ones, which are hardly to be met in the body of the world animal.

While it is puzzling how the World-Soul meets its object of cognition, it seems quite clear what the objects of cognition themselves are supposed to be: most people agree that the pair skedastén/ameriston in [1] stands for the same as the pair aisthéton/logistikon in [3] and [4], and that they refer to the familiar pair of realms of sensible and intelligible objects.

i Cf. p. 84 and note 26 (pp. 98-99) of Edward N. Lee's paper "Reason and Rotation: Circular Movement as the Model of Mind (Nous) in Later Plato," in: W. H. Werkmeister (ed.), Facets of Plato's Philosophy, van Gorcum, Assen 1976, pp. 70-102.

Still, it is not clear how much of freedom that intentionality has to focus on its object: in Tim. $40 \mathrm{a}-\mathrm{b}$ the heavenly gods are forced by the circular motion to think the same thoughts all the time (see also De Anima 407a 30-32 - but cf. Laws 901d ff. where heavenly gods have knowledge of everything both sensible and intelligible). 
As that is normally supposed to be an exhaustive dichotomy, in effect we are told that anything could become an object of the World-Soul's cognition, and that there are two basic classes of such objects.

(b) To state exactly 'what the World-Soul's cognition consists of' would require taking sides on the philological battlefield at 37b1-3 (cf. my note 1 and 5). It is clear that the cognition is supposed to consist (at least partly) in determining what the object in question is identical with, and what it is different from (37a7-b1). It is, however, less clear whether the phrase 'both among (kata) the changeable ... and with regard to (pros) the immutable' is supposed to concern the classes of objects of cognition or the classes of predicates.

Admittedly, it would not say anything new if it concerns the classes of objects of cognition (see (a) above). Also, we need not be surprised if identity and difference with regard to sensibles is predicated about a sensible, and identity and difference with regard to forms about a form. But it would be interesting to know whether a predication across the realms is proclaimed here - a doctrine surely possible in Plato, ${ }^{\mathrm{i}}$ but controversial (e.g. criticized notoriously in the Parmenides).

Besides, close to our passage, the circle of the Same is repeatedly referred to as the circle of the Same and the Similar (tautou kai homoiou 36d, 39b, 39d, 40b, 42c). Should we conclude from this, that the

\footnotetext{
i On the one hand, a form functions as a paradigm for recognizing qualities of sensibles due to their likeness (as e.g. in the Euthyphro 6d-e); on the other hand, a form can be like some sensibles in some respect (e.g. being 'beautiful'), and unlike them in an other (e.g. being a form).
} 
predication of 'sameness' need not to be just the predication of identity (numeric, or - probably more often - eidetic), but also of similarity? ${ }^{\mathrm{i}}$

And finally, we do not quite know what else besides predication of sameness and difference (and possibly similarity) belongs to the soul's cognition. Surely, the second part of [1] suggests that the predication can concern not just the object as a whole, but also certain aspects of it or relations it enters (including spacial or temporal determination). But some seem to read the passage $37 \mathrm{~b} 1-3$ as admitting any kind of predication, not just those mentioned above.

The latter point leads to an interesting question - too big to be dealt with here - whether Plato perhaps refers to some theory of predication here, a program aiming at reducing all possible predications to those using sameness and difference (numeric and eidetic), the aspect or relation (pros ti), the 'when', and the 'where' (and possibly also a distinction between what is essential and what accidental), as suggested at $37 \mathrm{~b} 1-\mathrm{b} 3 .{ }^{\text {ii }}$

(c) The passages [3] and [4] are rather closely parallel. If we take the phrases doxai kai pisteis bebaioi kai alétheis and nous epistémé te as

\footnotetext{
i Taylor (1928) says that homoios can mean isos in the old Ionian scientific usage, but all examples he quotes concern just angles [p. 155].

ii A tentative reading of 37a $7-\mathrm{b} 3$ connected with that is based on the opposition between einai and xumbainein: it recognizes that it can be seen as strange to predicate that something xumbainei to an immutable entity, especially if it were to be 'where' and 'when'. Granted that, it seems plausible to read the passage hot ... aei (37b1-3) as saying what happens in the realm of the changeable (kata ta gignomena), namely that it is predicated by them how they (hekasta) relate to other changeable entities (pros hekaston) as well as to the immutable ones (pros ta kata auta echonta aei).

Cf. also Aristotle's Met. V, ix, on predication of tauton (accidentally or essentially), heteron and homoion.
} 
referring each basically to a single epistemological status (which can be conveniently called 'true opinion', resp. 'knowledge'), ${ }^{i}$ the main message of [3] and [4] is that (as expected) the successful cognition of sensibles reaches the status of true opinion, and the successful cognition of intelligibles the status of knowledge.

What remains puzzling is that in each case the correct function of only one circle is mentioned as a necessary condition of the corresponding successful cognition. In an extreme reading the other, non-mentioned circle would not play any role in each type of cognition (strong specialization). In a less extreme reading the circle mentioned would just play a more prominent role than the other in the corresponding type of cognition (quasispecialization). But it is worth noting that the text perhaps does not require any specialization really: maybe the correct function of both circles is required for a successful cognition in each case, and just not all necessary conditions of successful cognition are explicitly mentioned in [3] and [4].

I find the claim of 'strong specialization' somewhat implausible, since we know from [1] that in both cognition of sensibles and cognition of intelligibles it is sameness as well as otherness that is predicated. Thus, the specialization of circles regarding the type of object of cognition would require a lack of specialization regarding the type of predication, and both circle of the Same and circle of the Other would have to be able to

i See Taylor (1928), pp. 182-3. Brisson (Le même et l'autre dans la structure ontologique du Timée de Platon: Un commentaire systématique du Timée de Platon, op. cit.) agrees with Proclus's contraposition (In Tim. II, 312.9-12) of nous and doxa to epistémé and pistis, without much explanation (p. 351). Surely, there is room for a possible internal differentiation of the way the phrases refer to the corresponding epistemological status; I just do not follow that line of inquiry here. 
determine both sameness and otherness. ${ }^{\mathrm{i}}$ The plausibility of the 'quasispecialization' claim depends on what kind of prominence would be ascribed to the appropriate circle. Without stating clearly what the prominence of the appropriate circle consists in, however, there is not much point in stressing it.

(d) It is far from clear what is the supposed role of logos and communication in our passage, in which Plato refers to logos explicitly in [2] and implicitly in [1] (legei), and to certain kinds of communication (diangeilé, ménusé) in [3] and [4]. The logos is said to be 'without speech and sound', and while in [2] it is discussed as a result of the process of cognition, in [1] it seems to play an active role in the process itself. If we distinguish between the aspect of articulation of cognition (e.g. into a subject and a predicate), and the aspect of communication of it (primarily between various parts of the soul in our context), I see the role of logos in [1] and [2] predominantly in the sphere of articulation. ${ }^{\text {ii }}$

In [3] and [4], on the other hand, we are informed about some process of propagation of the (already achieved) cognition throughout the soul, in case of the cognition of sensibles by the circle of the Other, and in case of the cognition of intelligibles by the circle of the Same. That is, of course, puzzling: are we to suppose that the cognition is achieved just at one part of the soul, if it has to be propagated? What part is that? Is it

\footnotetext{
i That seems to be the position of Harold Cherniss in Aristotle's Criticism of Plato and the Academy, vol. I (Johns Hopkins Press, Baltimore 1944). His words 'each circle ... reports both identity and difference among its own objects' seem also to preclude predication across the realms, see his note 339 [p. 410].

ii Although the communicative aspect may be pointed at as well: see the word feromenos in [2], and the possible (though not preferable) attachment of dia pasés heautés to legei (instead of kinoumené) in [1].
} 
always the same part or not? How are we to understand the process of propagation? ${ }^{\mathrm{i}}$

To sum up, we have a pair of circles and three other basic pairs: /a/ types of objects (sensible and intelligible), /b/ types of predication (otherness and sameness), and /c/ epistemological statuses (opinion and knowledge). I claim that it would lead to an absurdity to have the circles specialized regarding both $/ \mathrm{a} /$ and $/ \mathrm{b} /$, ii since it would make it impossible to predicate sameness of sensibles and otherness of intelligibles. ${ }^{\text {iii }}$ Besides, I think one can read the text as suggesting that there is a strict correspondence between /a/ and /c/, but I don't think one has to. ${ }^{\text {iv }}$ Similarly, one can see the text as suggesting specialization of the circles regarding either /a/ or /b/, but again one doesn't have to. ${ }^{\mathrm{v}}$

i Cf. Aristotle's criticism of the role supposedly ascribed to the parts of the soul in the Timaeus in his De anima I, iii, 407a 16-18.

ii As far as I understand it, Brisson's commentary comes close to such an absurdity. The fact that Brisson speaks about logical affirmation and negation instead of predication of sameness and otherness (see his p. 348) does not make the latent absurdity less sharp: are we supposed to avoid affirmative statements about the sensibles and negative statements about the intelligibles? If not, how should we understand the claim that the circle of the Same (resp. of the Other) is on the one hand the seat of the cognition of intelligibles (resp. of sensibles), and on the other hand the principle of affirmation (resp. of negation)? (see pp. 351-2, 439)

iii A possible objection is that it may be all right not to predicate any identity of sensibles (because of the doctrine of flux). But: 1) still it is necessary to predicate otherness of intelligibles, 2) besides otherness, we may want to predicate some similarity of sensibles, and we may want the circle of the Same to take part in that, and 3) the text passage [1] seems to require that both sameness and otherness is predicated of sensibles anyway.

iv Is it entirely impossible to have some knowledge of sensibles - e.g. that they are in flux and corruptible? Or is that just a true opinion? And, is it entirely impossible to have any true opinion of intelligibles?

$\mathrm{v}$ The situation gets more complicated if we add one more pair: /d/ the types of objects (intelligibles, sensibles) with regard to which sameness or otherness is predicated. Those who want to make sense of the repeated remark that the principle 'like is known by like' is applied here (as Aristotle in De Anima 404b 17-18, and many others) have thus a third candidate: it could mean kinship of the cognitive faculty /a/ with the type of object, or /b/ 
IV. Of course, since we are told that our passage (and most of the Timaeus) should take only cum grano salis, we have to distinguish between the puzzles concerning the role of the circles etc. in Timaeus's story (as discussed above) and their relevance as to how we understand Plato's philosophy. The latter is part of a general question too big for just this small paper. I shall confine myself to mentioning briefly two or three points.

Out of the three topics preceding 'cognition' in the title of my paper, it is what was said about the pair the Same/the Other that has more of general relevance. That pair is generally regarded to play an important role in Plato's later ontology as well as in his logic of predication and (perhaps less generally) in his theory of cognition. I hope that some of the questions raised and positive interpretations suggested (in III. above) may be relevant for our understanding of Plato's philosophy despite the fact that they arise while dealing with a somewhat fantastic narrative.

It is less clear whether we have learnt something positive concerning the role of logos and of the circular motion. Still, some questions were raised which need to be answered by those who see the metaphor of the circular motion as being closely connected to the problem field of logos and the Same/the Other, as e.g. Patočka and Gadamer, ${ }^{\mathrm{i}}$ as well as by those who want to disconnect them completely, as e.g. Lee. ${ }^{\text {ii }}$

with what is recognized (predicated) about the object (sameness or otherness), or /d/ with the realm of comparison in predication (same/other with regard to intelligibles or sensibles).

i See Patočka, J., Aristotelés, jeho předchůdci a dědicové, Nakladatelství ČSAV, Praha 1964, pp. 32-35; and Gadamer, H.-G., Griechische Philosophie II (= Gesammelte Werke 6), J. C. B. Mohr, Tübingen 1985, pp. 113-114, 126, 144-5, 147, 251.

ii Lee, E. N., "Reason and Rotation: Circular Movement as the Model of Mind (Nous) in Later Plato", op. cit., pp. 80-83. Circular motion is for him a model of "overcoming all perspectival limitation' (p. 81); of 'a "grasp," ... unconstricted by limitation to any fixed, 
specific vantage-point, but taking its "object" all at once and all-round" (p. 82); of 'subjectivity entirely absorbed in and subordinated to the apprehension of its object, wholly reduced to an abstract, pure aboutness' (p. 83). Can that be reconciled with the role of logos, of the Same and the Other in articulation of knowledge? 